\title{
Additive Manufacturing Technique for Corrosion less Bicycle Rim Production in Developing Countries like India
}

\author{
${ }^{1}$ Dr. M. K. Marichelvam, ${ }^{2}$ Mrs. M. Geetha, \\ ${ }^{1}$ Department of Mechanical Engineering, Mepco Schlenk Engineering College, Sivakasi, Tamilnadu, \\ India \\ ${ }^{2}$ Department of Mathematics, Kamaraj College of Engineering and Technology, \\ Virudhunagar, Tamilnadu, India
}

\begin{abstract}
Manufacturing of cycle rim by conventional methods needs more man power and many machine tools that increase the cost in developing countries such as India. Moreover, the secondary and tertiary operations associated with rim manufacturing pollute the environment. Assembly is another tedious process either by human beings or by machines. In order to overcome these difficulties an attempt is made in this work to design and develop a corrosion less bicycle rim using the additive manufacturing technique. Different models are developed and analyzed and the results are impressive.
\end{abstract}

Keywords: cycle rim, manufacturing, assembly, additive manufacturing, design and development.

\section{INTRODUCTION}

People use bicycle in different parts of the world for transportation, racing and exercise purpose. The bicycle consists of many number of components. Among them Rim is one of the most important components. The bicycle rims are produced in various designs and sizes based on the size of cycle and or design of bicycle. Generally the bicycle wheel is an assembly of rim and tire joined by tight fitting. This grip is achieved by the geometry profile of the rim and the tire. As the growing rate of bicycle industry is much faster in India, the need for bicycle rims is also increased in India. The various components of a bicycle rim are:

- Wheel hub

- Spokes

- Nipples

- Eye washers

These components are shown in Figure 1. One of the most important parts of a bicycle wheel is hub and it transmits torque from sprocket to the tire through spokes in the case of rear wheels. But in the case of front wheel it converts the push/pull given by the forks to rolling motion. Spokes are the connecting members which are pre-tensioned to assemble rim with the hub. Different types of spokes are used in bicycle manufacturing. Nipples are the specialized nuts to attach the spokes with the rim under tension. Each and every components of the bicycle rim is manufactured individually by using various machineries. The typical step by step manufacturing processes for the rim may be found in [38].

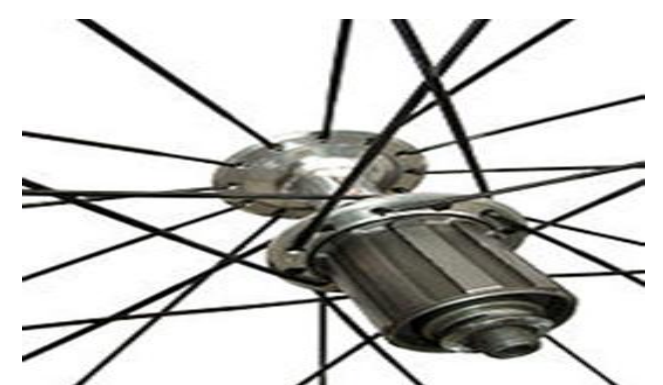

WHEEL HUB

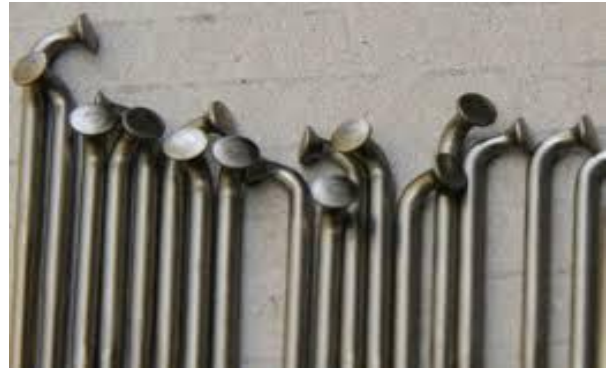

SPOKES 


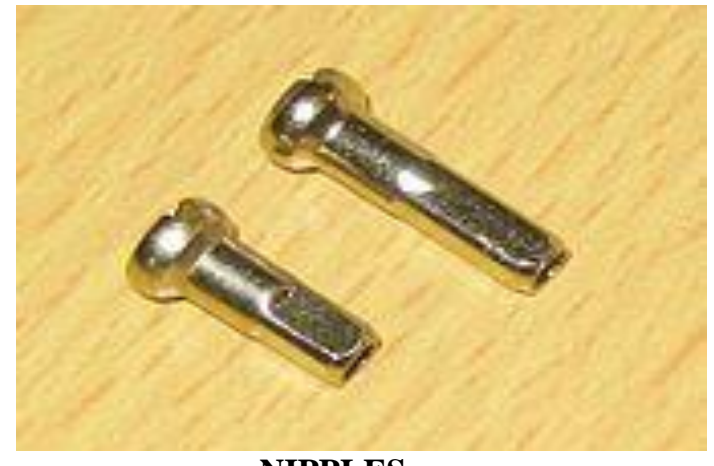

NIPPLES

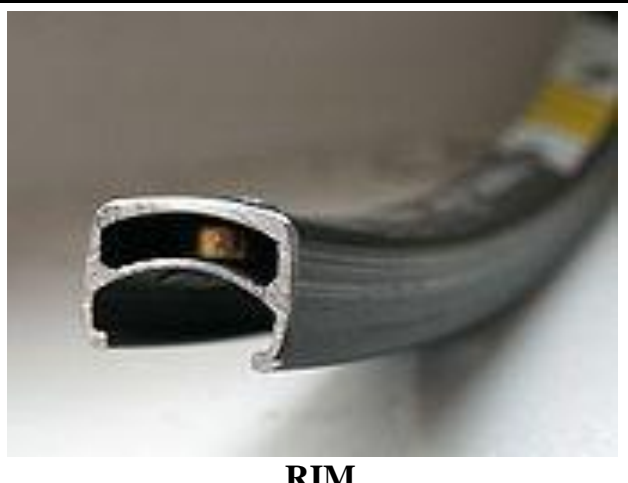

RIM

Figure1.Various components of a bicycle rim

The conventional bicycle rim manufacturing requires more number of machine tools and operators. Moreover, assembly is also a problem. In order to overcome these difficulties an attempt is made in this work to produce the bicycle rim by additive manufacturing (AM) technology.

Additive manufacturing (AM) is a process used to fabricate complex, net-shaped metal components in successive layers by rapid prototyping technique. With the help of AM several advantages could be achieved such as shorter lead time, low material and machining cost and less environmental problems [1]. Different techniques in AM can also be found in [1]. Rapid prototyping is a recently developed technique. It is used to produce shaped parts by gradual creation or addition of solid material, therein differing fundamentally from forming and material removal manufacturing techniques [16]. The term $\mathrm{AM}$ is described as a pool of production techniques assisting the layer-by-layer manufacture of component. The digital data and raw material are used as inputs [2]. AM also supports the engineers to generate substances from personalized specific computer-aided designs, while employing automated processes and standardized materials as building blocks. A new method based on computer aided design for AM was proposed in [4]. The AM was used for biomedical applications [5]. The potential environmental impacts of RP was discussed in [6]. The applications of AM technologies to medicine and health care field were presented in [7]. The significance of introducing new manufacturing processes was described in [8]. The rapid manufacturing technique was proposed for the spare parts industry [9]. An innovative method was cultivated to design and manufacture customized exact-fit medical implant [10]. A composite hemi-knee joint based on rapid prototyping (RP) technique was addressed in [11]. Researchers also proposed the rapid manufacturing technology for the spare parts supply chain [12]. Emerging rapid manufacturing processes were demonstrated in [13]. The Stereo lithography technique was demonstrated in [14]. Researchers have analyzed the possibility of manufacturability to combine additive and subtractive processes [15].

Several innovative production procedures were developed by the researchers to produce the parts growing the material gradually to obtain the needed profile [17]. The applications of RP in various field of engineering and technology were addressed in [18]. The detailed review and developments in ink-jet print technology were studied in [19]. The RP technique in dentistry: technology and application was studied in [20]. The solid freeform manufacturing processes were analyzed with respect to ecological performance [21]. Design and analysis of wheel rim using design soft wares such as CATIA \& ANSYS were carried out in [22]. Tissues and organs were produced using AM by the researchers [23]. Researchers also studied the environmental aspects of different industries such as laser-based and conventional tool and die manufacturing industries [24]. One of the most important techniques, the Laser Engineered Net Shaping process was presented in [25]. The environmental influence of machining processes were demonstrated by using models [26]. Different aspects such as process mechanics, wear characteristics and lubricant flows were integrated in the analytical model. The compassion of environmental factors with respect to variations in machining parameters were also inspected. A detailed comparison of different RP techniques were made in [27].

The three dimensional printing technique was explained in [28]. A ritual mandible titanium tray was designed and fabricated by rapid prototyping in [29]. Computer-aided design and rapid prototyping techniques were used to develop the Customized maxillo-facial prosthesis [30]. The process of Inkjet printing and its applications were addressed in [31]. ) The use of RP technique to promote medical implants was discussed in [32]. The impact of rapid manufacturing on supply chain methodologies 
and practice was addressed in [33-34]. Several advanced AM techniques were presented in [35]. The process cost appraisal for conventional and near net-shape cermet fabrication was proposed in [36].

From the literature it is evident that there is no reported application of the AM technique for the bicycle rim production. Hence, in this paper it is decided to design and fabricate a bicycle rim using the additive manufacturing technique. The rest of the paper is organized as follows. The problem definition is presented in section 2. The material selection will be presented in section 3. Section 4 demonstrates the proposed AM technique. Finally, conclusions are drawn in section 5.

\section{Problem Definition}

As discussed in the previous section many operations are required to produce the bicycle rim from cold rolled closed annealed (CRCA) sheet. This sheet is generally made up of mild steel which is then electroplated to improve its corrosion resistance. This is the principal reason for the rim failure. Secondly, the residual stress created during the various manufacturing processes. The tensile residual stress causes mild cracks over the surface of the base material which then develops and influences the rim failure in course of time. As the rim is to be welded, it leads to weld decay (corrosion of the grain boundaries in the heat affected zones) and cause knife line attack. Without any external load, the residual stresses may be in equilibrium within a part. These stresses are retained from a previous operation and are called as residual stresses. Residual stresses are developed in machining operations. The residual stresses present in cold rolled sheets and strips causes irregular shape and the residual stresses in cold rolled sheets are two dimensions both in longitudinal and transverse direction. The Residual stresses have foremost impact on the properties and contour of sheets. Due to the residual stresses cold rolled strips change their geometry and properties [39]. The problems with existing rim are shown in Figure 2.
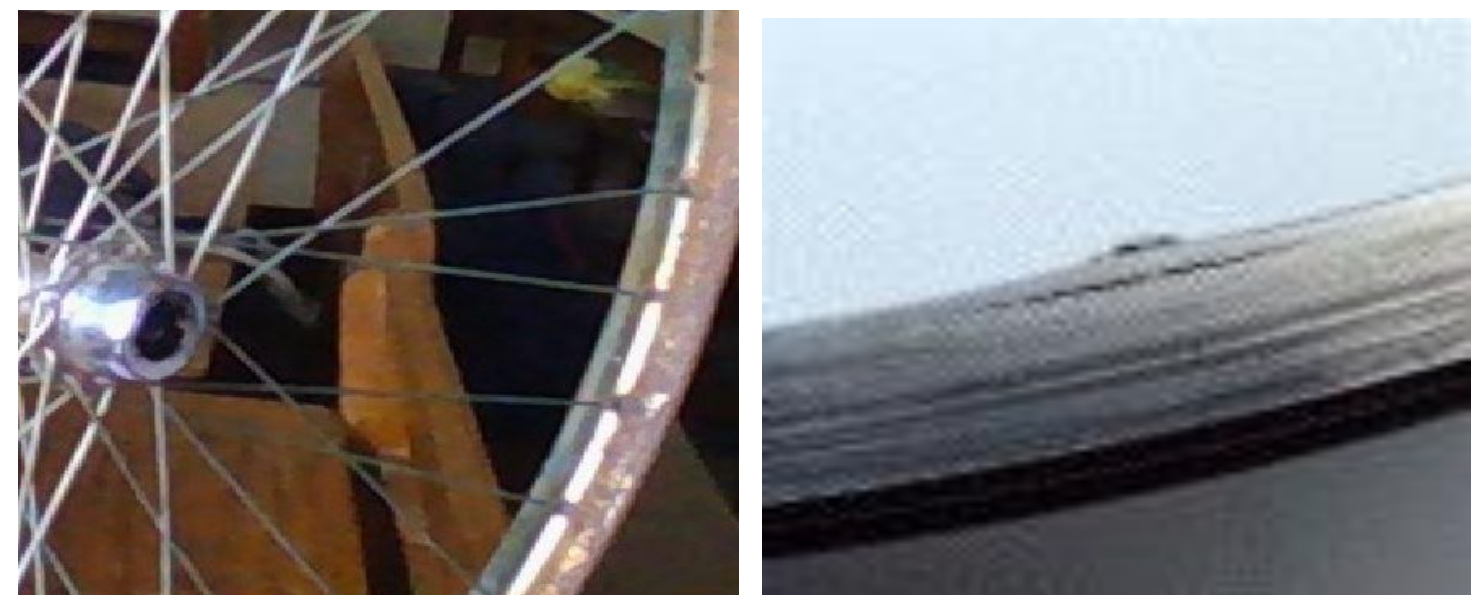

Figure2. Problems with existing rim

Moreover, in conventional technique steel rim is produced by combination of several production techniques. It takes more cycle time and it is very tedious to assemble those parts.

- It needs variety of machineries for manufacturing processes thus increasing the number of machines, operators and large floor area for production.

- Many machining processes are required which creates residual stress and material wastage.

- More power consumption due to the need of hydraulic pressing units and rolling unit.

- Secondary operations like grinding and buffing are required for finishing.

- Electro plating is also carried as tertiary operation to improve corrosion resistance.

- The effluents let out from electro plating process cause environmental pollution.

- Miscellaneous equipments for lacing (assembling) and balancing (truing) are also required.

The above problem can be solved by changing the material in such a way that the corrosion resistance would get increased. Secondly, the issue incorporated with the manufacturing processes which cause the post failure of the rim due to cracks could be solved by introducing a new manufacturing process 
in which no machining is carried out. Hence, in this paper an attempt is made to produce a bicycle rim using an additive manufacturing technique. The objective of this study are:

- To design and develop a model of bicycle rim to improve its corrosion resistance and hence increases the durability

- To improve the aesthetic appearance of the product.

- To do machining less process thus eliminating the residual stress.

- To select a manufacturing process in which Design modifications for the products can be easily attained.

- To eliminate material wastage and disposal.

- To reduce operator fatigue, manufacturing methods \& machinery requirements.

- To eliminate the need for balancing and lacing machines.

- To reduce the number of components thus eliminating the assembling process

\section{Material Selection}

As discussed in the previous section the material used for existing bicycle rim does not possess corrosion resistance properties. So, the existing material is to be replaced by the material which has such electro chemical potential to avoid or reduce the failure due to corrosion. Therefore, the material selection is done by the following way. Stainless steels are engineering materials with good corrosionresistance, strength and fabrication characteristics. They can readily meet a wide range of design criteria, including load, service life and low maintenance. The selected material is AISI 302.

The chemical composition of the selected material (AISI 302) grade is given below,

$\begin{array}{ll}\text { - Carbon } & 0.15 \% \\ \text { - Silicon } & 1.0 \% \\ \text { - Manganese } & 2.0 \% \\ \text { - Phosphorus } & 0.045 \% \\ \text { - Sulphur } & 0.03 \% \\ \text { - Nickel } & 8.00-10.00 \% \\ \text { - Chromium } & 17.00-19.00 \%\end{array}$

\section{Proposed AM Technique}

Additive manufacturing (AM) is a process of making a three-dimensional solid object of virtually any shape from a digital model. AM uses an additive process, where materials are applied in successive layers (usually layer upon layer) [40]. Each layer is a cross section of the part derived from a three dimensional model. As the layers get thinner the accuracy of the part increases. Machines typically have a printing head on an $\mathrm{XY}$ motion system with a $\mathrm{Z}$ axis that moves the model as each layer is added. Earlier AM equipment and materials were developed in the 1980s. AM has a 26-year history for plastic objects the capacity to make metal objects relevant to the engineered products and high tech industries has been around since 1995. The study therefore focuses on metal AM technologies. Additive manufacturing technology is used for both prototyping and distributed manufacturing with applications in different fields. Additive manufacturing is also known as 3-D printing. Also Rapid Prototyping (RP) is a term, most commonly used to describe a variety of processes, which are aimed at quickly creating three-dimensional physical parts from virtual 3D computer models using automated machines. The parts are "built" directly from the 3D CAD model and can match that model very closely (within the precision limits of the chosen process). Rapid prototyping is different from traditional fabrication in that it is only possible through the use of computers, both to generate the 3D CAD model data, as well as to control the mechanical systems of the machines that build the parts. Virtually all RP processes are "additive". Parts are built up by adding, depositing, or solidifying one or more materials in a horizontal layer-wise process. The part is built up layer by layer until done. 
This is similar to the result one would get if one made a topographical map of the object, with the contour lines representing the layer thickness of the process. 3D CAD models can be made with many, many different software packages each will have its own way of representing surfaces and volumes. The problem for the user is to be able to prepare this model for 3D printing or Rapid prototyping. In general, what is needed is one or more completely closed volumes. The RP software may be able to understand and automatically correct small openings and errors, but large holes or open objects will result in not being able to print (without the file being first repaired).

Since different programs work in different ways and have different file formats, it will be necessary to "translate" the representation of the model in that software into something more "universal" that the RP software can understand. This translation process can introduce problems into the process that were not apparent in the original. In general, from the 3D CAD software, we need to export the model as a .STL file. Nearly all 3D programs can export an STL and most can import them. An STL is a type of standardized computer exchange file which contains a 3D model. The representation of the surface(s) of the object(s) in the file is in the form of one or more polygon meshes. The polygon meshes in an STL file are entirely composed of triangular faces, edges and vertices. Further, the faces have assigned normals which indicate their orientation (inside/outside).

The name "STL" is taken from its extension, .stl, originally because the files were intended for the rapid prototyping process called Stereo lithography. The file format has become a world standard for exchanging 3D polygon mesh type objects between programs, and .stl's are now used as input for virtually all rapid prototyping processes, as well as some 3D machining. RP technique has the following advantages:

$\square$ Reduce the time of new product development.

Launch new products well-ahead of competitors.

Concept prototypes can be made faster.

Design can be frozen early.

Multiple working prototypes in a very short time for testing \& evaluation.

Drawings released to vendors after design validation.

The steps in the AM techniques are as follows [3]:

1) Drawing the object in CAD model.

2) Convert the file in to STL format.

3) Set up Machine.

4) Build.

5) Remove.

6) Post processing.

7) Application.

There are many types based on the materials used, application, form of the material fed for manufacturing, namely,

$\square$ Stereo lithography (SLA)

Laminated Object Manufacturing (LOM)

$\square$ Selective Laser Sintering (SLS)

$\checkmark$ Fused Deposition Modeling (FDM)

$\square$ Solid Ground Curing (SGC)

3D-Printing (3DP) 
$\square$ Direct metal laser sintering (DMLS)

Among these manufacturing techniques, Direct Metal Laser Sintering (DMLS) could be suitable for the production of bicycle rim since this technique is capable of manufacturing stain less steels which is selected for the application. But, it is decided to do fabrication of the model of the proposed bicycle rim in Fused Deposition Modeling (FDM) in this project. The details of FDM could be found in [37].

As discussed earlier, the selected manufacturing process is additive manufacturing which does not involve any kind of machining processes thus eliminating the material wastage and its disposal. And, this process require only the sliced model in .STL format which is the input for the additive manufacturing machine. This.STL file conversion could be done by using various 3D model formats. In order to input such .STL format, the 3D model of the required product is to be created. As we all know that 2D drawings (orthographic views) of the proposed model are indispensable for modeling, these 2D drawings are to be prepared by manually(hand drawings) or by using drafting software's like Auto CAD, Solid works, etc.,

However it is better to prepare using such software's due to many advantages, namely

- Design changes/editing can be easily attained,

- Dimensions are automatically generated,

- Drawings can be documented safely,

- No need for such drawing equipments,

- Time saving method,

- Can be used for better communications, etc.

However, we used solid works package for the preparation of $2 \mathrm{D}$ drawings and for creating 3D models, as it is user friendly. The different models developed are shown in Figure 3.
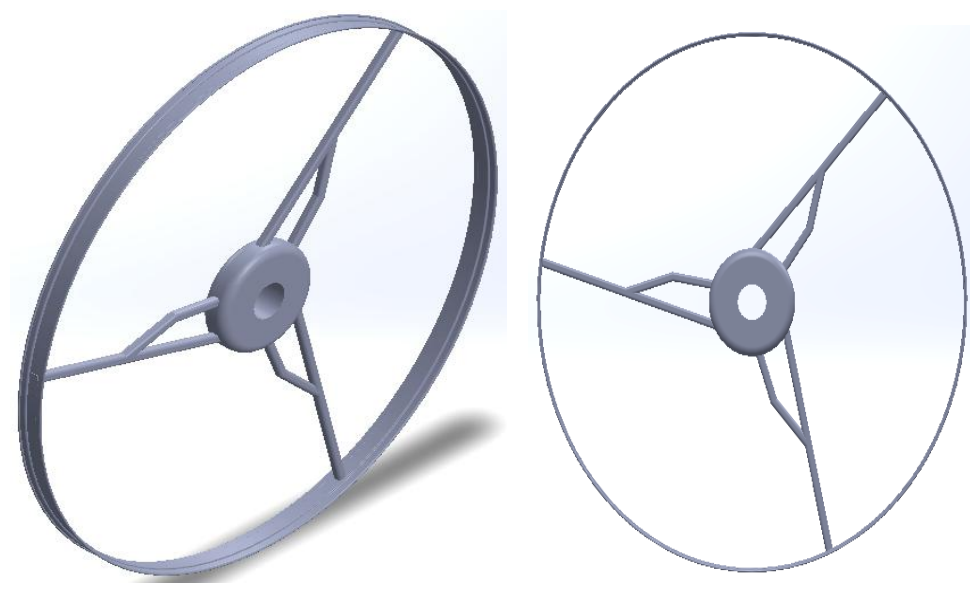

MODEL-1

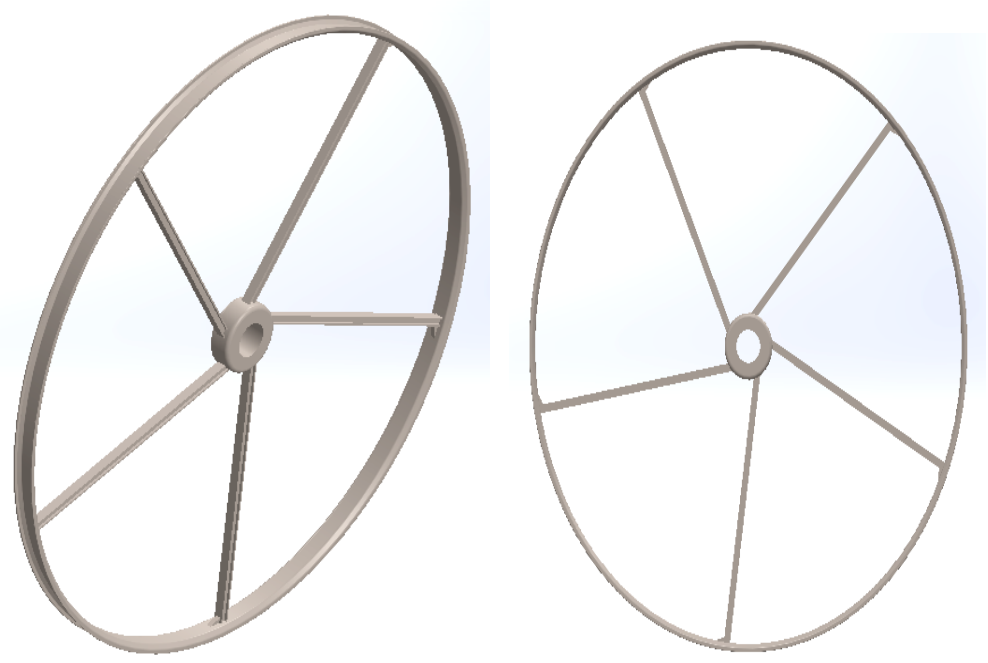




\section{MODEL-2}

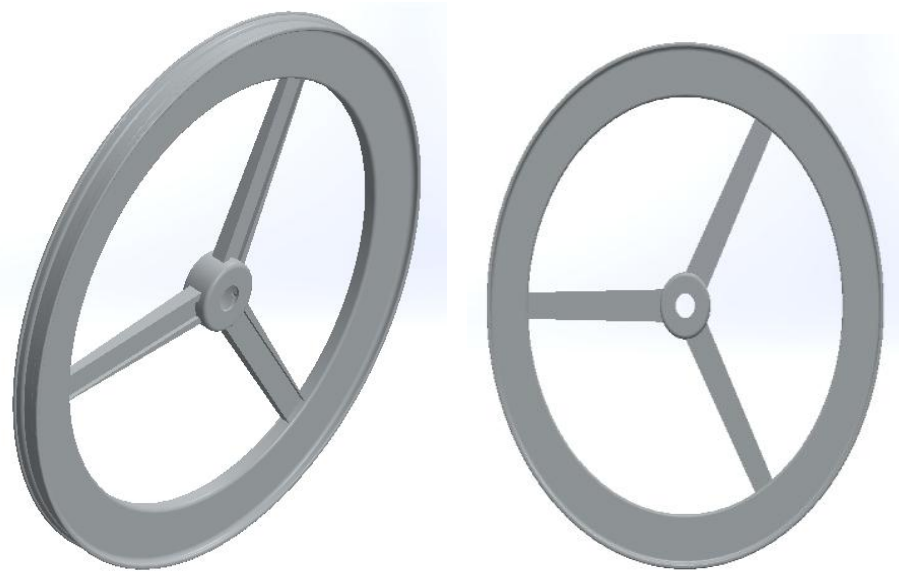

MODEL-3
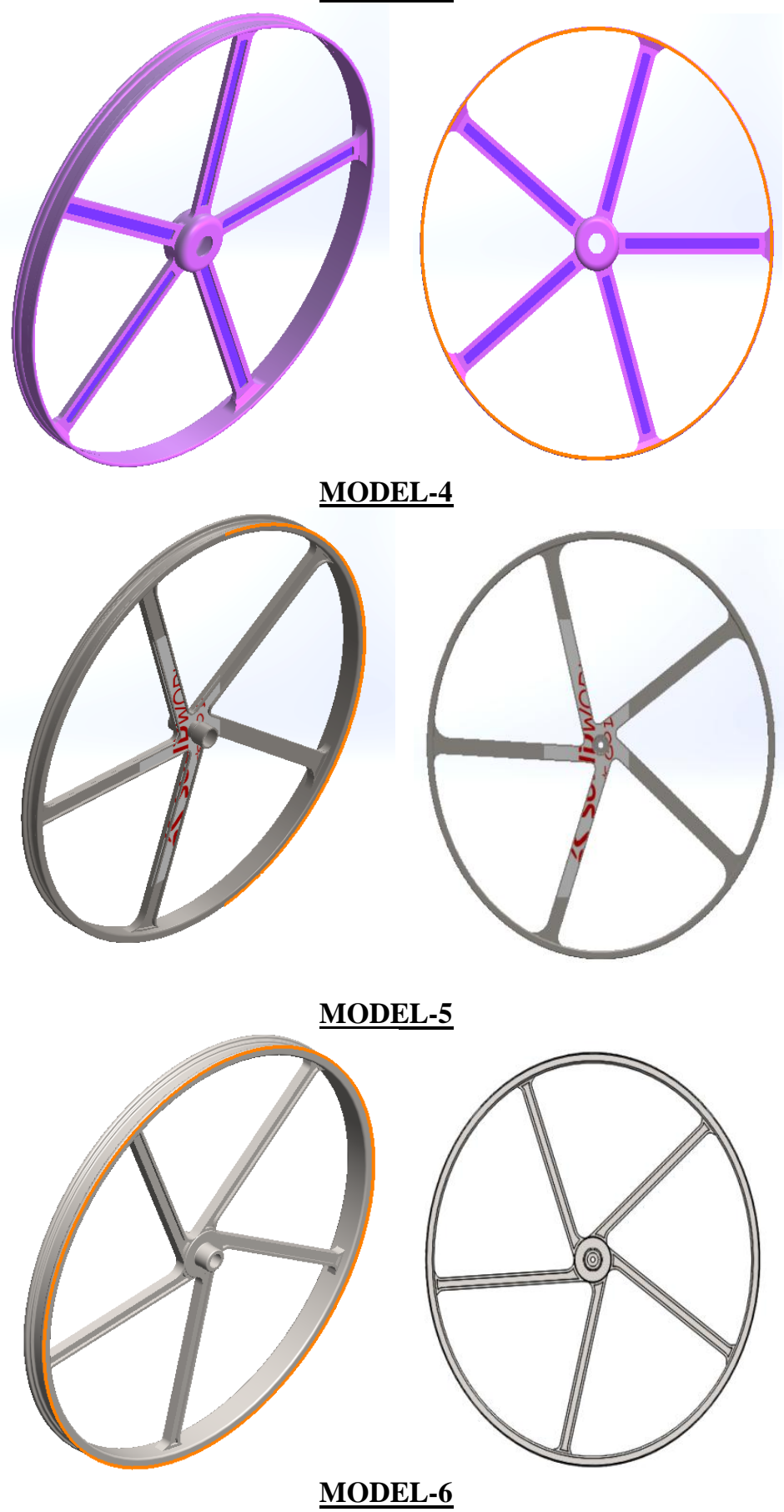

International Journal of Modern Studies in Mechanical Engineering (IJMSME) 
Figure3. Models developed

\subsection{Load Calculation}

To evaluate the model whether it will satisfy the requirements for which it is intended, the adequate analysis is to be carried over. In order to do analysis the model created so far the load exerting on the rim is to be calculated. This can be calculated by considering the total mass laid on the bicycle frame which in turns goes to the hub of the bicycle wheel eventually. As discussed in the previous chapter, the solid works premium has been selected for analysis also.

Let $\mathrm{W}$ be the total load on the bicycle,

For analysis, the load on the single wheel is to calculated $(\mathrm{F})$,

$\mathrm{F}=\mathrm{W} / 2$

$\mathrm{W}=$ weight of the cycle +weight of the rider

$=200+800$

$=1000 \mathrm{~N}$,

Including FOS $=4$ by considering the road conditions and increase in the load,

Actual load $=1000 * 4$

$=4000 \mathrm{~N}$.

Therefore, the load/wheel, $\mathrm{F}=4000 / 2$

$\mathrm{F}=2000 \mathrm{~N}$.

\subsection{Analysis}

The steps in analysis are as follows:

1. Importing the model

2. Material selection

3. Fixture constraints

4. Application of load

5. Meshing the model

6. Running the study

The models were meshed in solid works software using the following parameters.

$\begin{array}{ll}\text { Analysis type } & \text { Buckling } \\ \text { Zero strain temperature } & \text { 298 Kelvin } \\ \text { Unit system } & \text { SI (MKS) } \\ \text { Length/Displacement } & \mathrm{mm} \\ \text { Pressure/Stress } & \mathrm{N} / \mathrm{m}^{2} \\ \text { Mesh type } & \text { Solid Mesh } \\ \text { Meshes Used: } & \text { Standard mesh }\end{array}$

\subsection{Fabrication process}

The steps involved in the fabrication parts are given below,

1. Slicing

2. Support structure generation

3. Manufacturing

\subsubsection{Slicing}


The part was oriented in horizontal orientations and was sliced uniformly to trade-off among the three stated objectives satisfying the constraints (presence of support structure trapped volume, large horizontal planes and small or thin features). The slicing technique was successfully done using INSIGHT software for adequate accuracy and the file was converted into .STL format. The slicing parameters are:
1. Height
$=14 \mathrm{~mm}$
2. Slicing Thickness
$=0.075757 \mathrm{~mm}$

\subsubsection{Support structure generation}

An adequate support structure is required for the fabrication. This structure is used to support the material which is not directly in contact with the bottom layer. This is also used to avoid the interference of the hanging layers to the bottom layer or ground.

\subsubsection{Manufacturing}

The fabrication was done in FDM machine. The specification of the machine is given below.

\subsubsection{Technical specifications}

Materials

Build envelope

Layer thicknesses

Support structure

System size/weight
ABS-M30

914 × $610 \times 914 \mathrm{~mm}(36 \times 24 \times 36$ in. $)$

$0.254 \mathrm{~mm}(0.010 \mathrm{in}$.

Water Soluble Material

$2772 \times 1683$ × $2027 \mathrm{~mm}(109.1 \times 66.3 \times 79.8$ in. $) /$ with crate: 3287 $\mathrm{kg}$ (7247 lbs.), without crate: $2869 \mathrm{~kg}(6325 \mathrm{lbs}$.)

Achievable accuracy $\quad: \quad \pm .09 \mathrm{~mm}( \pm .0035 \mathrm{in}$.$) or \pm .0015 \mathrm{~mm} / \mathrm{mm}( \pm \quad .0015 \mathrm{in} / \mathrm{in})$, whichever is greater. (Accuracy is geometry dependent. Achievable accuracy specification derived from statistical data at $95 \%$ dimensional yield.)

Network communication

10/100 base T connection; Ethernet protocol

Power requirement 230VAC nominal three-phase service with $5 \%$ regulation

The fabricated model is shown in Figure 4.

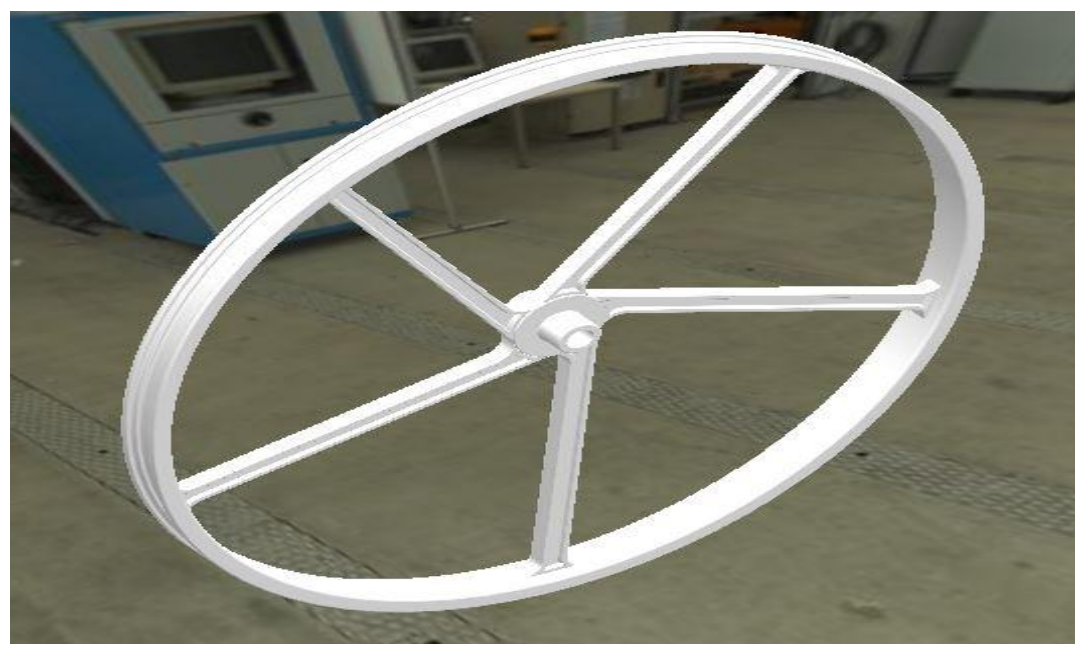

Figure4. Fabricated model

\section{CONCLUSIONS AND FUTURE RESEARCH}

Thus the design and development of the corrosion less bicycle rim by additive manufacturing was successfully done. The additive manufacturing technique would be a boon for the developing countries such as India. To the best of our knowledge, this is the first attempt to produce a corrosion 
less bicycle rim using additive manufacturing technique. The manufacturing of the complex parts which require various machining operations could also be done. The processes require many operators as well as the tedious design procedures could also be carried out using this additive manufacturing process. This project could be expanded for the production of other automobile components which is very complex in design and manufacturing.

\section{REFERENCES}

[1] Baufeld, B., Van der Biest, O., \& Gault, R. (2010). Additive manufacturing of Ti-6Al-4V components by shaped metal deposition: microstructure and mechanical properties. Materials \& Design, 31, S106-S111.

[2] Baumers, M, Tuck, C, Bourell, DL (2011) Sustainability of additive manufacturing: measuring the energy consumption of the laser sintering process. IMechE Part B: J Eng Manuf 225: pp. 2228-2239

[3] Bordoni, M., \& Boschetto, A. (2012). Thickening of surfaces for direct additive manufacturing fabrication. Rapid Prototyping Journal, 18(4), 308-318.

[4] Chu, C, Graf, G, Rosen, DW (2008) Design for additive manufacturing of cellular structures. Comput Aided Des Appl 5: pp. 686-696

[5] Cohen DL, Lipton JI, Bonassar LJ, Lipson H. Additive manufacturing for in situ repair of osteochondral defects. Biofabrication 2010; 2:035004/1-12.

[6] Drizo, A, Pegna, J (2006) Environmental impacts of rapid prototyping: an overview of research to date. Rapid Prototyping J 12: pp. 64-71

[7] Giannatsis, J, Dedoussis, V (2009) Additive fabrication technologies applied to medicine and health care: a review. Int J Adv Manuf Tech 40: pp. 116-127

[8] Gutowski TG, Branham MS, Dahmus JB, Jones AJ, Thiriez A (2009) Thermodynamic analysis of resources used in manufacturing processes. Environ Sci Technol 43:1584-1590

[9] Hasan S, Rennie A (2008) The application of rapid manufacturing technologies in the spare parts industry. Solid Freeform Fabrication Symposium, University of Texas at Austin, pp 584-590

[10] He, Y, Ye, M, Wang, C (2006) A method in the design and fabrication of exact-fit customized implant based on sectional medical images and rapid prototyping technology. Int J Adv Manuf Tech 28: pp. 504-508

[11] He, J, Li, D, Lu, B (2006) Custom fabrication of a composite hemi-knee joint based on rapid prototyping. Rapid Prototyping J 12: pp. 198-205

[12] Holmstrom, J, Partanen, J, Tuomi, J, Walter, M (2010) Rapid manufacturing in the spare parts supply chain: alternative approaches to capacity deployment. J Manuf Tech Manag 21: pp. 687697

[13] Hopkinson, N, Dickens, PM Emerging rapid manufacturing processes. In: Hopkinson, N, Hague, RJM, Dickens, PM eds. (2006) Rapid manufacturing - an industrial revolution for the digital age. John Wiley, Chichester, pp. 55-80

[14] Hull, C (1988) Stereolithography: plastic prototype from CAD data without tooling. Mod Cast 78: pp. 38-58

[15] Kerbrat, O, Mognol, P, Hascoët, JY (2010) Manufacturability analysis to combine additive and subtractive processes. Rapid Prototyping Journal 16:pp. 63-72

[16] Kruth, JP, Leu, MC, Nakagawa, T (1998) Progress in additive manufacturing and rapid prototyping. CIRP Ann-Manuf Techn 47: pp. 525-540

[17] Kruth, JP (1991) Material in cress manufacturing by rapid prototyping techniques. CIRP AnnManuf Techn 40: pp. 603-614

[18] Kumaravelan R, Sathish Gandhi V.C, Ramesh.S, Venkatesan M (2014) Rapid Prototyping Applications in Various Field of Engineering and Technology.International Journal of Mechanical, Aerospace, Industrial and Mechatronics Engineering 8:pp.604-608

[19] Le, HP (1998) Progress and trends in ink-jet print technology. J Imaging Sci Techn 42: pp. 49-62

[20] Liu, Q, Leu, MC, Schmitt, SM (2006) Rapid prototyping in dentistry: technology and application. Int J Adv Manuf Tech 29: pp. 317-335 
[21] Luo YC, Ji ZM, Leu, et al. (1999) Environmental performance analysis of solid freeform fabrication processes. The 1999 IEEE Int Symp on Electron and the Environ. IEEE, NY, pp 1-6

[22] Meghashyam, Girivardhan Naidu and Sayed Baba (2013) Design and Analysis of Wheel Rim using CATIA \& ANSYS, International Journal of Application or Innovation in Engineering \& Management 2:pp.14-20

[23] Melchels, F. P., Domingos, M. A., Klein, T. J., Malda, J., Bartolo, P. J., \& Hutmacher, D. W. (2012). Additive manufacturing of tissues and organs. Progress in Polymer Science, 37(8), 10791104.

[24] Morrow, WR, Qi, H, Kim, I, Mazumder, J, Skerlos, SJ (2006) Environmental aspects of laserbased and conventional tool and die manufacturing. J Clean Prod 15: pp. 932-943

[25] Mudge, RP, Wald, NR (2007) Laser engineered net shaping advances additive manufacturing and repair. Weld J 86: pp. 44-48

[26] Munoz, AA, Sheng, P (1995) An analytical approach for determining the environmental impact of machining processes. J Mater Process Tech 53: pp. 736-758

[27] Pham, DT, Gault, RS (1998) A comparison of rapid prototyping technologies. Int J Mach Tool Manu 38: pp. 1257-1287

[28] Sachs, E, Cima, M, Cornie, J (1990) Three dimensional printing: rapid tooling and prototypes directly from a CAD model. CIRP Ann-Manuf Techn 39: pp. 201-204

[29] Singare, S, Dichen, L, Bingheng, L, Yanpu, L, Zhenyu, G, Yaxiong, L (2004) Design and fabrication of custom mandible titanium tray based on rapid prototyping. Med Eng Phys 26: pp. 671-676

[30] Singare, S, Yaxiong, L, Dichen, L, Bingheng, L, Sanhu, H, Gang, L (2006) Fabrication of customized maxillo-facial prosthesis using computer-aided design and rapid prototyping techniques. Rapid Prototyping J 12: pp. 206-213

[31] Singh, M, Haverinen, HM, Dhagat, P, Jabbour, GE (2010) Inkjet printing: process and its applications. Adv Mater 22: pp. 673-685

[32] Truscott, M, Beer, D, Vicatos, G, Hosking, K, Barnard, L, Booysen, G, Campbell, IR (2007) Using RP to promote collaborative design of customised medical implants. Rapid Prototyping J 13: pp. 107-114

[33] Tuck, C, Hague, R, Burns, N (2007) Rapid manufacturing: impact on supply chain methodologies and practice. IJSOM 3: pp. 1-22

[34] Walter M, Holmstrom J, Yrjola H (2004) Rapid manufacturing and its impact on supply chain management. LRN Annu Conf, September 9-10, Dublin, Ireland

[35] Wohlers, T (2012) Additive manufacturing advances. Manuf Eng 4: pp. 55-63

[36] Xiong, Y, Schoenung, JM (2010) Process cost comparison for conventional and near net-shape cermet fabrication. Adv Eng Mater 12: pp. 235-241

[37] Zein, I., Hutmacher, D. W., Tan, K. C., \& Teoh, S. H. (2002). Fused deposition modeling of novel scaffold architectures for tissue engineering applications. Biomaterials, 23(4), 1169-1185.

[38] http://www.dcmsme.gov.in/reports/mechanical/bicyclerims.pdf (accessed on 04.06.2017)

[39] https://www.efatigue.com/training/Chapter_8.pdf (accessed on 04.06.2017)

[40] http://www.rolandberger.com/media/pdf/Roland_Berger_Additive_Manufacturing_20131129.pd f (accessed on 04.06.2017) 


\section{AUTHORS' BIOGRAPHY}

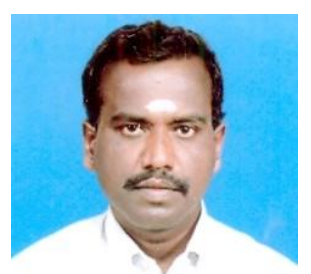

M. K. Marichelvam, received his B.E. degree in Mechanical Engineering from Madurai Kamaraj University, Madurai, India, in 2000. He has obtained a Masters in Engineering in Industrial Engineering from Madurai Kamaraj University, Madurai, India, in 2002. He has obtained Ph.D. in Mechanical Engineering from Anna University, Chennai, India in 2015. He is currently working as Assistant Professor in Mechanical Engineering Department, Mepco Schlenk Engineering College, Sivakasi, India. His active areas of interests are Manufacturing Scheduling, Multi-objective optimization, Industrial and Production Management and optimization techniques. He has published many research papers in the Journals of International repute. He has presented papers at several international conferences.

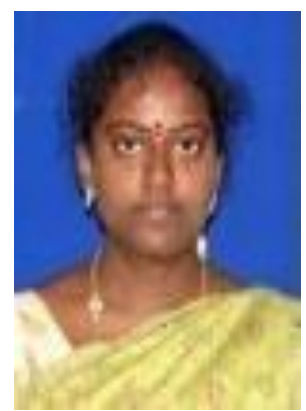

M. Geetha received her B.Sc. degree in Mathematics from Madurai Kamaraj University, Madurai, India, in 2005 and her M.Sc. degree in Mathematics from Madurai Kamaraj University, Madurai, India, in 2007. She has obtained her M.Phil. degree in Mathematics from Madurai Kamaraj University, Madurai, India, in 2008. She has been working as Assistant Professor in the department of Mathematics, Kamaraj College of Engineering and Technology, Virudhunagar, India since 2008. Her main research interests are Graph theory and optimization techniques. She has published many research papers in the Journals of International repute. 